\title{
A Rapid Method for Detection of Cold Hardiness in Roses
}

\section{Fadi H. Karam and J. Alan Sullivan \\ Department of Horticultural Science, University of Guelph, Guelph, Ont. N1G 2W1, Canada}

Additional index words. Rosa fedtschenkoana, Rosa hybrida CV. Jack Frost, sucrose, cold acclimation, freezing

\begin{abstract}
Distinct differences in freezing tolerance among a cold-hardy wild rose species Rosa fedtschenkoana Regel., a garden rose, 'Jack Frost', and their hybrid could be detected under laboratory conditions using 2 -cm-long shoot segments with buds. The garden rose did not survive - SC, but the cold-hardy species survived freezing to $-10 \mathrm{C}$ and the hybrid to $-5 \mathrm{C}$. One week of acclimation at $4 \mathrm{C}$ was adequate for $R$. fedtschenkoana; longer periods did not improve the rate of survival. Immersing tissue in $5 \%, 10 \%$, or $20 \%$ sucrose during acclimation improved the rate of survival of $R$. fedtschenkoana but not of 'Jack Frost'. Applications to rose breeding are discussed.
\end{abstract}

In breeding experiments, the most common and certain way of assaying for cold resistance in plants is by exposure to the natural winters for a minimum of two seasons (Svejda, 1979). Unfortunately, winter seasons vary in their severity, and the uniformity of experimental conditions is not guaranteed. To provide uniform conditions, special controlled-temperature chambers can be used, but the number of plants that can be tested is limited and these facilities may not be available to all programs. A procedure to assay for cold hardiness in laboratory conditions using tissue culture could be a solution, provided in vitro and field-grown plants would respond to cold treatments in a similar fashion.

Caswell et al. (1986) investigated cold hardiness of in vitro shoots of apple and saskatoon (Amelanchier alnifolia Nutt.) by exposing the shoots to freezing temperature $(-3 \mathrm{C})$ for $16 \mathrm{hr}$, then lowering the temperature by $2 \mathrm{C} / \mathrm{hr}$ in a programmable freezer. Shoots were then removed from the freezer at various temperatures, allowed to thaw for $24 \mathrm{hr}$ at $2 \mathrm{C}$, and cultured on fresh medium to test for survival.

A rose breeding program was started at Guelph in 1977 to introduce cold hardiness into garden roses. Identifying cold-hardy hybrids has been tedious and time-consuming, comprised of growing the seedlings in the greenhouse, then moving them to the field and observing their survival over 2 or more years. In this paper we describe a simple and rapid method to assay for cold hardiness in roses under laboratory conditions.

A cold-hardy wild rose species, Rosa fedtschenkoana, a cold-sensitive hybrid tea cultivar, Jack Frost, and their $F_{1}$ hybrid were

Received for publication 12 Jan. 1990. We thank the Ontario Min. of Agriculture and Food and the Dunnington-Grubb Foundation for their financial support of this project. The cost of publishing this paper was defrayed in part by the payment of page charges. Under postal regulations, this paper therefore must be hereby marked advertisement solely to indicate this fact. used in this experiment. Plants were grown in a greenhouse with a minimum and maximum of 17 and $20 \mathrm{C}$, respectively. They were fertilized every 2 weeks with 400 ppm $20 \mathrm{~N}$ 20P-20K soluble fertilizer, and continuous supplementary lighting was provided from fall into spring (October to April) by high-pressure sodium lights providing a light intensity of $80 \mu \mathrm{mol} \cdot \mathrm{s}^{-1} \cdot \mathrm{m}_{2}$ at plant level at the top of the canopy. Actively growing shoots were harvested in Spring and Fall 1989. Differences between genotypes were assayed in the spring (March to April) and the effect of sucrose and period of acclimation were tested in separate experiments conducted in the fall (October to November). The upper $15 \mathrm{~cm}$ of the shoot was discarded and the remainder used as a source of budded segments (10 to 20 ) each $\approx 2 \mathrm{~cm}$ long. Each segment of current-season stems was considered to have similar hardiness levels (Carrier, 1952). These segments were immersed in sucrose solutions of different concentrations $(0 \%, 5 \%$, $10 \%$, and $20 \%$ ) at $4 \mathrm{C}$ for periods of 1 to 4 weeks before being exposed to freezing temperatures of -5 or $-10 \mathrm{C}$ for $18 \mathrm{hr}$. They were then thawed at $4 \mathrm{C}$ for $24 \mathrm{hr}$, surfacesterilized, and cultured on Murashige and Skoog (1962) medium. The culture tubes were placed in a growth room at $24 \pm 2 \mathrm{C}$ and 16 -hr light period. Growth of buds was observed 2 weeks after culturing and used as a means of assaying for survival.

The experimental design was a completely randomized design consisting of four replications of each treatment. The mean of 10 shoot segments per replication was used in the analysis of variance. Differences among means were tested using regression analysis and Tukey's (HSD) where appropriate.

There was a clear difference in freezing tolerance between the three rose genotypes. Only the wild species $R$. fedtschenkoana survived freezing at $-10 \mathrm{C}$. The hybrid survived $-5 \mathrm{C}$ and 'Jack Frost' suffered lethal injuries at both temperatures (Table 1). The results were consistent with our observations of the outdoor behavior of these roses for four winters at the Cambridge Research Farm near Guelph. R. fedtschenkoana and the hybrid, but not 'Jack Frost', survive the winter weather of southern Ontario where the temperature may drop briefly to as low as $-25 \mathrm{C}$. Correlations between cold hardiness of excised tissue and whole plants have been reported in other plant species including potato (Chen et al., 1979; Sukumaran and Weiser, 1972), spinach (Guy et al., 1987), and chrysanthemum (Bannier and Steponkus, 1976).

Sucrose treatment during acclimation was beneficial in increasing the survival of buds. Soaking 'Jack Frost' shoot segments in sucrose solution did not enhance their resistance to freezing, whereas soaking $R$. fedtschenkoana did. There was a distinct difference in survival of $R$ fedtschenkoana buds as a result of acclimating tissue in 5\%, 10\%, or $20 \%$ sucrose solution compared to water alone. Maximum survival occurred at $10 \%$ sucrose (Table 2). Increasing the sucrose levels up to $14 \%$ in tissue culture media resulted in increased cold tolerance in apple and saskatoon shoots (Caswell et al., 1986), Solarium suspension cultures (Hellergren and Li, 1981), and many other species (Levitt, 1980). Natural sugar content in plants usually increases with increased cold tolerance (Levitt, 1980).

None of the shoot segments, including $R$. fedtschenkoana, survived freezing without acclimation. There were significant linear and quadratic responses of percent survival to 0 , 1,2 , and 4 weeks of acclimation. One week of acclimation in $10 \%$ sucrose resulted in $78 \%$ survival. Longer periods (i.e., up to 4 weeks) did not improve rate of survival above $85 \%$. Duration and other cold acclimation requirements differ for various species, but the need for an acclimation period is a universal requirement (Levitt, 1980). Nevertheless, some plants fail to acclimate and remain very sensitive to freezing. Our results indicate that 'Jack Frost' probably belongs to this category of plants in that its resistance to cold was improved neither by sucrose treatment nor by acclimation at low temperature.

From these results we conclude that assaying for cold hardiness could be accomplished in a laboratory environment within 2 weeks, thus saving an appreciable amount of time and effort. This method would be es-

Table 1. Percent survival of shoot segments with budsoftworosetaxa Rosa fedtschenkoana (R.F.) and $R$. hybrida CV. Jack Frost (J. F.) and their $\mathrm{F}_{1}$ hybrid $(\mathrm{J} \times \mathrm{R})$ after exposure to freezing at -5 or $-10 \mathrm{C}$ for $18 \mathrm{hr}$ (after acclimation for 2 weeks in $10 \%$ sucrose solution at $4 \mathrm{C}$ ).

\begin{tabular}{lcr}
\hline \hline & \multicolumn{2}{c}{ Survival (\%) } \\
\cline { 2 - 3 } & \multicolumn{2}{c}{ Freezing temp $\left({ }^{\circ} \mathrm{C}\right)^{y}$} \\
\cline { 2 - 3 } Genotype & -5 & -10 \\
\hline R.F. & $100 \mathrm{a}$ & $82 \mathrm{a}$ \\
J $\times$ R & $68 \mathrm{~b}$ & $0 \mathrm{~b}$ \\
J.F. & $0 \mathrm{c}$ & $0 \mathrm{~b}$
\end{tabular}

${ }^{2}$ Data are the means of four replicates, 10 buds per replication.

${ }^{y}$ Values in columns followed by same letter are not significantly different using Tukey's HSD $(P=0.05)$. 
Table 2. Percent survival of shoot segments with buds of Rosa fedtschenkoana (R.F.), R. hybrida CV. Jack Frost (J.F.), and their hybrid (J X R) after freezing to $-10 \mathrm{C}$ as influenced by acclimation for 2 weeks at $4 \mathrm{C}$ in various sucrose solutions.

\begin{tabular}{lccc}
\hline \hline & \multicolumn{3}{c}{ Survival (\%) } \\
\cline { 2 - 4 } & \multicolumn{3}{c}{ Genotype } \\
\cline { 2 - 4 } Sucrose concn (\%) & R.F. & J x R & J.F. \\
\hline 0 & $28^{2}$ & 0 & 0 \\
5 & 53 & 0 & 0 \\
10 & 88 & 0 & 0 \\
20 & 80 & 0 & 0 \\
Significance & & & \\
$\quad$ Linear & $* *$ & NS & NS \\
$\quad$ Quadratic & $* *$ & NS & NS \\
\hline
\end{tabular}

${ }^{2}$ Data are the means of four replicates, 10 buds per replication.

**, NsSignificant at $P=0.01$ and nonsignificant, respectively.

pecially efficient in expansive breeding programs dealing with numerous plant cultivars and hybrids being evaluated for winter hardiness. Laboratory evaluation for cold hardiness would assist in the elimination of coldsensitive genotypes during early generation testing. This selection process we describe may not identify the most hardy individuals in the population, but can certainly be valuable as a means of eliminating the least or moderately hardy types. Only long-term field testing can identify winter survival. This technique for selection for winter hardiness must be used judiciously to avoid restriction of genetic variability and reduction in progress from selection. Winter field survival has been the most elusive process to study and evaluate when breeding for cold resistance because several environmental factors interact to affect the genotypes tested (Blum, 1988). However, in the present. study, the observed in vitro reaction of these genotypes was typical of the response observed over four winters in the field. $R$. fedtschenkoana has shown no visible injury and 'Jack Frost' dies to soil level each winter, while injury on the hybrid is limited to the thinner portions of the cane. These results indicate this technique has application in rose breeding programs where winter hardiness is a desirable trait. .

\section{Literature Cited}

Bannier, L.J. and P.L. Steponkus. 1976. Cold acclimation of chrysanthemum callus cultures. J. Amer. Soc. Hort. Sci. 101:409-412.

Blum, A. 1988. Plant breeding for stress environments. CRC Press, Boca Raton, Fla.

Carrier, L.E. 1952. Low temperature tolerance of rose plant portions as influenced by their diameter and position in the plant. Proc. Amer. Soc. Hort. Sci. 59:501-508.

Caswell, K. L., N.J. Tyler, and C. Stushnoff. 1986. Cold hardening of in vitro apple and saskatoon shoot cultures. HortScience 21(5):1207-1209.

Chen, H. H., P. Gavinlertvatana, and P.H. Li. 1979. Cold acclimation of stem-cultured plants and leaf callus of Solarium species. Bot. Gaz. 140:142-147.

Guy, C.L., R.L. Hummel, and D. Haskell. 1987. Induction of freezing tolerance in spinach during cold acclimation. Plant Physiol. 84:868-871.
Hellergren, J. and P.H. Li. 1981. Survival of Solanum tuberosum suspension cultures to $-14 \mathrm{C}$ The mode of action of proline. Phydiol. Plant. $52: 449-453$.

Levitt, J. 1980. Responses of plants to environmental stresses. 2nd. ed. vol. 1. Academic, New York.

Murashige, T. and F. Skoog. 1962. A revised me- dium for rapid growth and bioassays with tobacco tissue cultures. Physiol. Plant. 15:473497.

Sukumaran, N.P. and C.J. Weiser. 1972. An excised leaflet test for evaluating potato frost tolerance. HortScience 7:467-468.

Svejda, F. 1979. Inheritance of winter hardiness in roses. Euphytica 28:309-314. 